\title{
Synthesis and application of calixarene-based functional material for arsenic removal from water
}

\author{
Imdadullah Qureshi · Shahabuddin Memon
}

Received: 14 May 2011 / Accepted: 6 March 2012/Published online: 4 April 2012

(C) The Author(s) 2012. This article is published with open access at Springerlink.com

\begin{abstract}
The present article represents synthesis and As(III) sorption behavior of a novel calix[4]arene-appended functional material (DE-4 resin). The sorption ability of DE-4 resin has been evaluated at wide range of $\mathrm{pH}$, i.e., $\mathrm{pH}$ 2-14. It has been observed that the DE-4 resin possesses greater interaction for As(III) with maximum sorption capacity ( $88 \%$ at $\mathrm{pH} 4)$. Column sorption mechanism was studied through various parameters, i.e., change in concentration, flow rate, and bed heights. The results obtained by changing these parameters were compared with the theoretically calculated. From the results it has been observed that DE-4 resin has maximum column efficiency of $412 \mu \mathrm{g} \mathrm{g}^{-1}$. Thermal behavior of the synthesized DE-4 resin was examined at various temperatures from 298 to $338 \mathrm{~K}$, which shows that column efficiency increases with increase in temperature. From the DSC study it has been observed that DE-4 resin is stable up to $439 \mathrm{~K}$. Concerning regeneration ability DE-4 resin was found to be regenerable and best regeneration was achieved using $5 \%$ solution of $\mathrm{HNO}_{3} / \mathrm{NaOH}$. It can be deduced from the study that the resin will find its applicability in small as well as industrialscale water purification plants.
\end{abstract}

Keywords Calix[4]arene - Arsenite sorption - BDST model $\cdot$ Solid-phase extraction $\cdot$ Breakthrough curve

I. Qureshi · S. Memon $(\bowtie)$

National Center of Excellence in Analytical Chemistry,

University of Sindh, Jamshoro 76080, Pakistan

e-mail: shahabuddinmemon@yahoo.com

\section{Introduction}

Ample clean and pure water is among the basic human rights, but the presence of several toxic metals in huge quantity altered the purity of water. Among the toxic metals, arsenic is the most common toxicity-causing metal. It is a cosmopolitan ecotoxine and every year millions of people in the whole world are victims of the poisonous effects of the toxin. It is present in surface as well as ground waters. In aerobic surface water it is present in pentavalent form, i.e., $\mathrm{As}(\mathrm{V})$ or arsenate and under anaerobic conditions in ground water; it is present in trivalent form, i.e., As(III) or arsenite. Arsenic enters to the environment through several natural processes like weathering, emissions from volcanoes, and biological processes (Zouboulis and Katsoyiannis 2002; Wolthers et al. 2005; Maji et al. 2007). Many anthropogenic activities like mining of gold, non-iron-based smelting, petroleum refineries, power plants, arsenical composed herbicides or pesticides, etc., (Chen et al. 2010) are also responsible for the existence of arsenic in ground as well as surface waters. Because of its ubiquitous nature, it induces many adverse hazards on human health. Globally and specially in the developing countries a huge majority of population is suffering from arsenic containing water-borne diseases like keratosis, pigmentation, lung and liver cirrhosis, and kidney cancer. WHO and US EPA recommended maximum level of arsenic contamination in drinking water is $10 \mu \mathrm{g} \mathrm{L}^{-1}$ (WHO 1996; EPA 2002). On the bases of serious hazards to human health, its removal is a burning issue of today's active research. In this regard a large number of treatment techniques are applied for the removal of arsenic from contaminated waters, which can be categorized into (1) membrane-driven techniques, e.g., nanofiltration, reverse osmosis, or electro dialysis (Waypa et al. 1997; Minhas 
et al. 2010a, b; Wu et al. 2011); (2) precipitation/coagulation technique, e.g., coagulation with iron or aluminum salts or lime softening (Zouboulis and Katsoyiannis 2002); and (3) adsorption processes, such as adsorption on activated alumina, on iron oxides, or synthetic resins (Qazi et al. 2010a, b, c; Qureshi et al. 2010; Memon et al. 2004a, b). Among these techniques sorption is the efficient, easily applicable and economical one. The process of sorption through synthetic sorbent has got much application because the synthetic resins have regeneration ability and are also thermally/chemically stable. Among these resins Amberlite XAD-4 has got wide application because of high porosity, good chemical/physical properties, and easy modification through various ligating groups. Among these ligating groups, calixarene, which is a new macrocyclic class of supramolecular chemistry, offers enormous application in the field of separation and purification sciences. The aromatic core of calixarenes has the capability to be functionalized with numerous metal-ligating moieties, which can be applied for the removal of toxic metals (Qazi et al. 2010a, b, c; Kartinen and Christopher 1995; Shih 2005; Akceylan et al. 2006] as well as in developing ion selective electrodes for the detection of toxic metal ions (Durmaz et al. 2011). The stable aromatic backbone of calixarene can be further strengthened both in efficiency and stability by incorporating into a polymeric support. These calixarene appended resins with greater surface area and thermal stability can be effectively applied for the removal of toxic metals especially arsenic.

Thus, in continuation to our previous efforts of anchoring calixarene core with efficient functionalities and then developing regenerable synthetic resins (Qureshi et al. 2008, 2009; Minhas et al. 2010a, b; Kamboh et al. 2009; Memon et al. 2004a, b); herein we report another XAD-4supported calixarene-based DE-4 resin, which has greater surface area and high capability to effectively bind the target metal ion, i.e., As(III).

\section{Materials and method}

\section{Instrumentation}

781- $\mathrm{pH} / \mathrm{Ion}$ meter with $\mathrm{Ag}, \mathrm{Ag} / \mathrm{Cl}$ reference electrode 6.0726.100 (Metrohm Herisau Switzerland) was used to measure the $\mathrm{pH}$. Initially, arsenic was determined through 747 Computrace polarograph (Metrohm, Herisau Switzerland) and then verified by atomic absorption spectrometer (model Analyst 700 supplied by Perkin-Elmer Corp. PerkinElmer (Shelton, CT, USA)). The working parameters of arsenic-hollow cathode lamp were adjusted according to the manufacturer instructions. Surface coverage/sorption was confirmed by FT-IR spectrometer (model AVATAR 5700 from Thermo Nicollet). FT-IR spectra were recorded in the form of $\mathrm{KBr}$ pellets from 4,000 to $400 \mathrm{~cm}^{-1}$ range. Elemental analyses were performed using (Flash EA 1112 elemental analyzer). JSM-6380 scanning electron microscope (SEM) was used to study surface morphology. Absorbance was measured by PerkinElmer Lambda 35 UV/Vis spectrophotometer using standard $1.00-\mathrm{cm}$ quartz cells. Thermal analysis was carried out using differential scanning calorimetry (DSC 822 (Mettler, Toledo)).

\section{Standard solutions and reagents}

Analytical grade sodium arsenite $\left(\mathrm{NaAsO}_{2}\right)$, concentrated $\mathrm{HCl}$ and $\mathrm{HNO}_{3}$ were acquired from Merck (Darmstadt, Germany). Arsenic stock solution of $1 \mathrm{mg} \mathrm{L}^{-1}$ was prepared on weekly bases. Calibration standards of arsenic $\left(1,000 \mu \mathrm{g} \mathrm{L}^{-1}\right)$ were prepared for each analytical session using certified stock standard solution (Fluka Kamica, Bushs, Switzerland). Nitric acid solution (5 M) was used for soaking all glassware and polyethylene bottles before use, and then washed with deionized water obtained by passing it through a Millipore Milli-Q water purifying system.

\section{Synthesis}

Calix[4]arene (1) and its derivative (2) were prepared according to the published procedures (Gutsche and Lin 1986; Genorio et al. 2008; Solangi et al. 2009). While in the present study, the modified synthetic procedures for $\mathbf{2}$ and its polymeric resin (DE-4 resin) as depicted in Scheme 1 have been discussed below.

\section{Synthesis of 25,26,27,28-tetrakis(2-ethoxyethoxy)} calix[4]arene (2)

The solution of 2-ethoxyethanol $(0.133 \mathrm{~mol}, 20 \mathrm{~g})$ in $50 \mathrm{~mL}$ tetrahydrofuran (THF) was added to the aqueous solution of sodium hydroxide $(0.2 \mathrm{~mol}, 8.0 \mathrm{~g})$ at $0{ }^{\circ} \mathrm{C}$, the whole mixture was stirred for half an hour. After that solution of $p$-toluenesulphonyl chloride $(0.133 \mathrm{~mol}, 25.4 \mathrm{~g})$ in $50 \mathrm{~mL}$ THF was added drop by drop and the mixture was subjected to further stirring for additional $2 \mathrm{~h}$. After that the mixture was poured into $10 \%$ ice-cold $\mathrm{HCl}$ solution, two layers were observed. Yellow oily layer was extracted using ethyl acetate and subjected to drying by addition of anhydrous sodium sulphate. Evaporation of solvent, i.e., ethyl acetate resulted yellow oily product (2-ethoxyethyl-4methylbenzenesulfonate), which was used directly for further reaction with the mixture of calix[4]arene (2) $(1.947 \mathrm{~g}$, $3.0 \mathrm{mmol}$ ) in $100 \mathrm{~mL}$ dry dimethylformamide (DMF) 


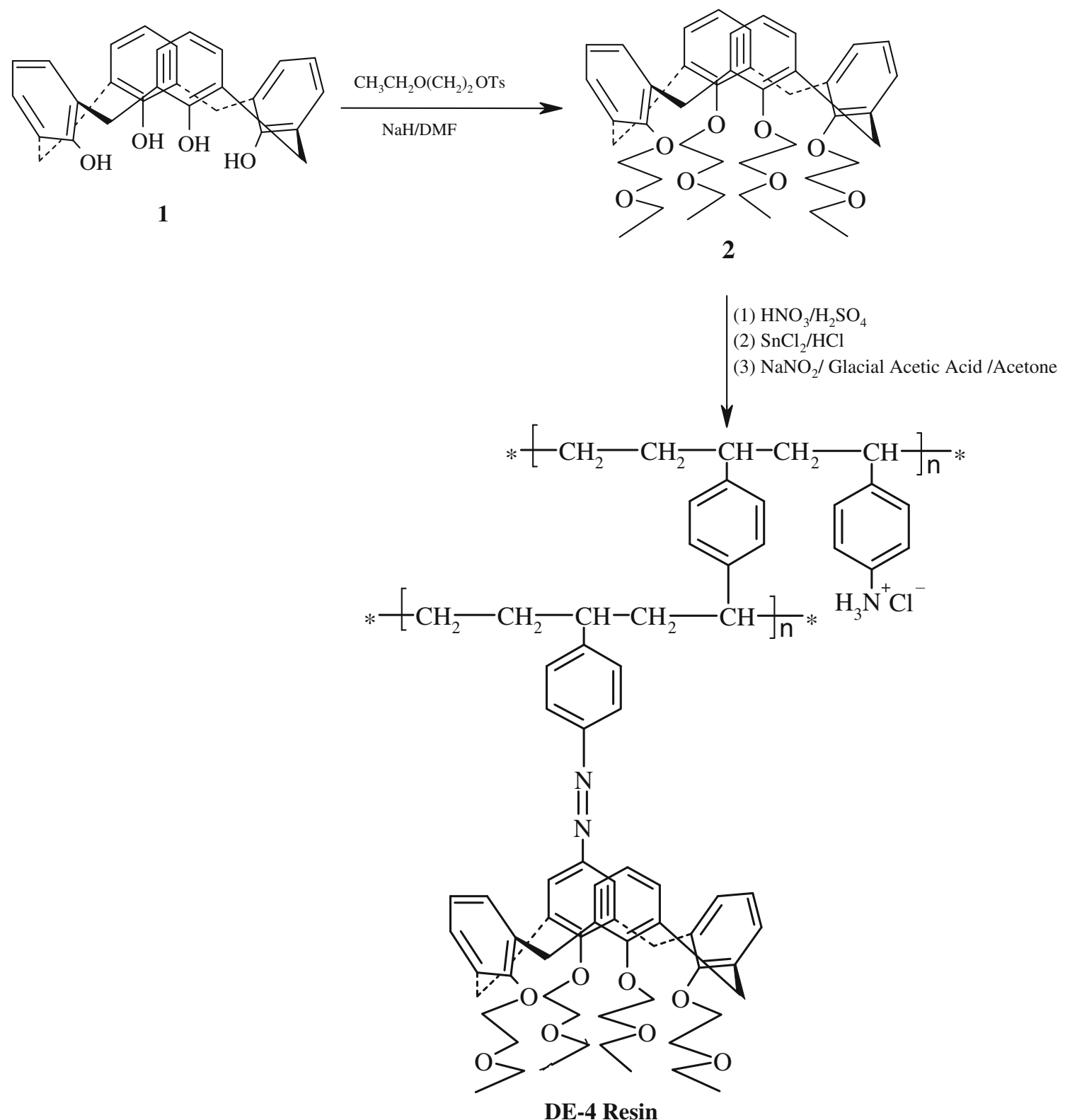

Scheme 1 A schematic representation of the synthesis of calix[4]arene derivative (2) and the corresponding polymeric DE-4 resin

containing sodium hydride $(\mathrm{NaH})(0.7 \mathrm{~g}, 29.13 \mathrm{mmol})$. The mixture was stirred for $1 \mathrm{~h}$ at room temperature. Then 2-ethoxyethyl-4-methylbenzenesulfonate $\quad(14.4 \mathrm{~g}, \quad 59.06$ mmol) was added and the mixture was heated to $80{ }^{\circ} \mathrm{C}$ for $72 \mathrm{~h}$. After that methanol was added to the cooled mixture, all the solvents were removed and the residue was dissolved in dichloromethane, acidified with $1 \mathrm{M} \mathrm{HCl}$ and washed with water. Evaporation of the dichloromethane and drying of the product furnished 2 in considerable yield $(1.5 \mathrm{~g}$, $65 \%$ ), m.p. $75^{\circ} \mathrm{C}$ (uncorrected). FT-IR (KBr) 1086 (C-OC) and $815 \mathrm{~cm}^{-1}\left(\mathrm{CH}_{3}\right)$. Elemental analysis: Found: $\mathrm{C}$, $74.09 \%$; $7.90 \%$; O, $17.95 \%$ calculated for $\mathrm{C}_{44} \mathrm{H}_{56} \mathrm{O}_{8}$ : C, $74.13 \%$; H, $7.92 \%$; O, $17.95 \%$.
Immobilization of 25,26,27,28-tetrakis(2-ethoxyethoxy)calix[4]arene (2) onto AmberliteXAD-4 (3)

Preparation of functionalized XAD-4 polymer was carried out according to the already reported procedure (Solangi et al. 2009). Amberlite XAD-4 (5.0 g) was first nitrated using $25 \mathrm{~mL} \mathrm{H}_{2} \mathrm{SO}_{4}$ and $10 \mathrm{~mL}$ of $\mathrm{HNO}_{3}$. The reaction mixture was stirred at $60{ }^{\circ} \mathrm{C}$ for $30 \mathrm{~min}$. After that the mixture was poured into ice-cold water and the nitrated resin filtered off. The resin was washed with excessive water until neutralization. The nitro groups of the resin were then reduced to amino groups by refluxing at $80{ }^{\circ} \mathrm{C}$ with the mixture of $\mathrm{SnCl}_{2}(15 \mathrm{~g}, 66.48 \mathrm{mmol}), 16 \mathrm{~mL} \mathrm{HCl}$ 
and $20 \mathrm{~mL}$ ethanol for $20 \mathrm{~h}$. After filtration the product was washed with water, followed by $2 \mathrm{M} \mathrm{NaOH}$, in order to neutralize and remove $\mathrm{SnCl}_{2}$. It was again washed with water and then dried.

For diazotization, it was suspended in $350 \mathrm{~mL}$ ice-cold water. After that $\mathrm{NaNO}_{2}(1.0 \mathrm{M})$ and $\mathrm{HCl}(1.0 \mathrm{M})$ solutions were added $1 \mathrm{~mL}$ each with intervals until the mixture changed the color of iodide paper to violet. The product was filtered washed with water and further reaction with 2 was carried out by suspending the mixture of diazotized resin and 2 in $350 \mathrm{~mL}$ glacial acetic acid and acetone in $3: 1$ mixture at below $3^{\circ} \mathrm{C}$ for $24 \mathrm{~h}$. After that color of the resin beads changed to light brown. Finally, the contents were filtered, washed with water followed by dichloromethane and then dried in vacuum oven at $60^{\circ} \mathrm{C}$. FT-IR (KBr) 1,452 (N=N), 1,086 (C-O-C) and $815 \mathrm{~cm}^{-1}$ $\left(\mathrm{CH}_{3}\right)$. Elemental analysis found: $\mathrm{C}, 74.37 \%$;, $7.90 \%$; $\mathrm{N}, 3.12 \%$. Calculated for $\mathrm{C}_{55} \mathrm{H}_{70} \mathrm{O}_{8}: \mathrm{C}, 74.46 \% ; \mathrm{H}$, $7.95 \% ; \mathrm{N}, 3.95 \%$.

\section{Sorption methods}

\section{Static method (batch method)}

The optimum $\mathrm{pH}$ of $\mathrm{As}(\mathrm{III})$ uptake by DE-4 resin was determined by static method. The $\mathrm{pH}$ of $\mathrm{As}(\mathrm{III})$ solution was adjusted prior to equilibrium by the addition of $0.1 \mathrm{M}$ $\mathrm{HCl}$ or $\mathrm{NaOH}$. After that $20 \mathrm{mg}$ of DE-4 resin was suspended in $25 \mathrm{~mL}$ of $\mathrm{As}(\mathrm{III})$ solution $\left(30 \mu \mathrm{g} \mathrm{L}^{-1}\right)$ and the mixture was agitated in a thermostatic shaker at room temperature until equilibrium has achieved. The time taken to reach equilibrium was $1 \mathrm{~h}$, after that the resin was filtered and the concentration of As(III) in the solution was determined through electro-analytical technique. The percentage arsenic sorption was calculated using Eq. (1).

$\% S=\left(C_{0}-C_{\mathrm{e}} / C_{\mathrm{s}}\right) \times 100$

where $C_{0}$ is the initial and $C_{\mathrm{s}}$ is the saturated concentration of $\mathrm{As}(\mathrm{III})$.

\section{Column sorption method}

Column study was carried out using glass column of $1 \mathrm{~cm}$ internal diameter and $40 \mathrm{~cm}$ length. It was packed with the DE-4 resin between two layers of glass wools to prevent floating of DE-4 resin. The sorption process was extensively evaluated through various parameters like, effect of $\mathrm{pH}$, change in initial concentration of $\mathrm{As}$ (III), flow rate, bed height, and temperature. The As(III) sorption behavior of DE-4 resin was tested at varying $\mathrm{pH}$, i.e., $\mathrm{pH} 2-14$. Column was operated in the down-flow mode at different concentrations of $\mathrm{As}$ (III) $\left(30,60\right.$, and $\left.100 \mu \mathrm{g} \mathrm{L}^{-1}\right)$ and bed heights of $(4,6$, and $10 \mathrm{~cm})$. For the sorption studies, the effect of flow rate was also evaluated from 2 to $6 \mathrm{~mL}$ $\min ^{-1}$. The thermodynamic studies were carried out in the temperature range of 298-338 K using modified column that was operated under controlled temperature system as expressed in Fig. 1. The exhausted packed column can be desorbed/regenerated using $5 \%$ solution of $\mathrm{HNO}_{3} / \mathrm{NaOH}$, which produces $98 \%$ recovery of $\mathrm{As}(\mathrm{III})$ at the flow rate of $2 \mathrm{~mL} \min ^{-1}$. After desorption the DE-4 resin bed actively sorbs As(III) with $\approx 1-2 \%$ loss in efficiency.

Analytical methods

\section{Electroanalytical method}

Arsenic in the effluent was determined using electroanalytical technique. All As(III) samples of varying concentrations were prepared from standard solution of $1,000 \mu \mathrm{g} \mathrm{L} \mathrm{L}^{-1}$ through dilution method. After passing through column, samples were acidified with hydrochloric acid and $0.2 \mathrm{~g}$ of hydrazine chloride was added to stop As(III) oxidation as reported by Sadana (1983). Determination of As(III) was carried out using saturated $\mathrm{Ag} / \mathrm{AgCl}$ and platinum wire as reference and auxiliary electrodes, while gold electrode was used as working electrode. Anodic stripping voltammetry technique was applied to determine As(III) in $10 \mathrm{~mL}$ solution of supporting electrolyte with $1 \mathrm{M}$ sulfuric acid and $0.1 \mathrm{M}$ hydrochloric acid. Other conditions were set as reported (Kopanica and Novotny 1998).

\section{UV-visible method}

Total arsenic was also verified through UV-visible spectrometer applying already reported method (Pillai et al. 2000). In this method $2 \mathrm{~mL}$ of rhodamine B $(0.05 \%)$, $2 \mathrm{~mL}$ of potassium iodate $(2 \%)$ and $1 \mathrm{~mL}$ of $\mathrm{HCl}(0.4 \mathrm{M})$

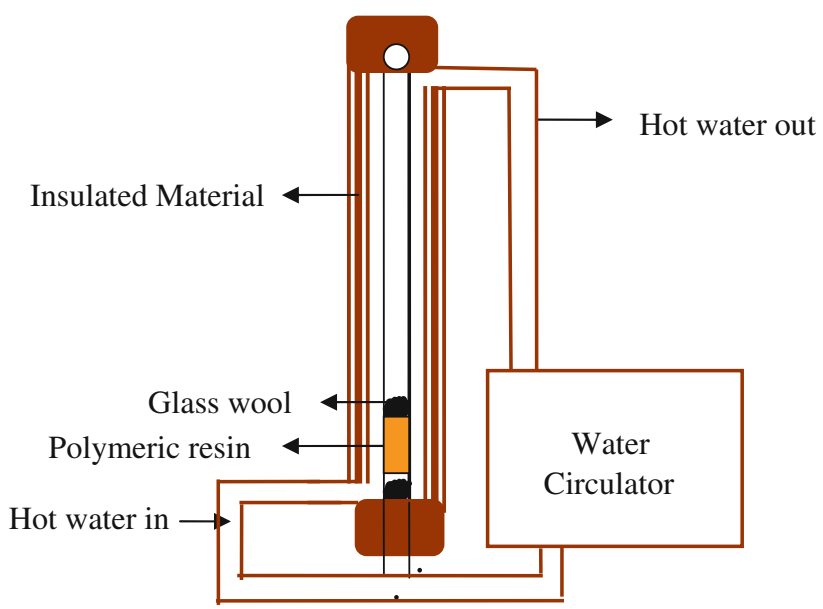

Fig. 1 Temperature control assembly 
Fig. 2 Scanning electron microscopic study of the surface morphology of a Amberlite XAD-4, b DE-4 resin
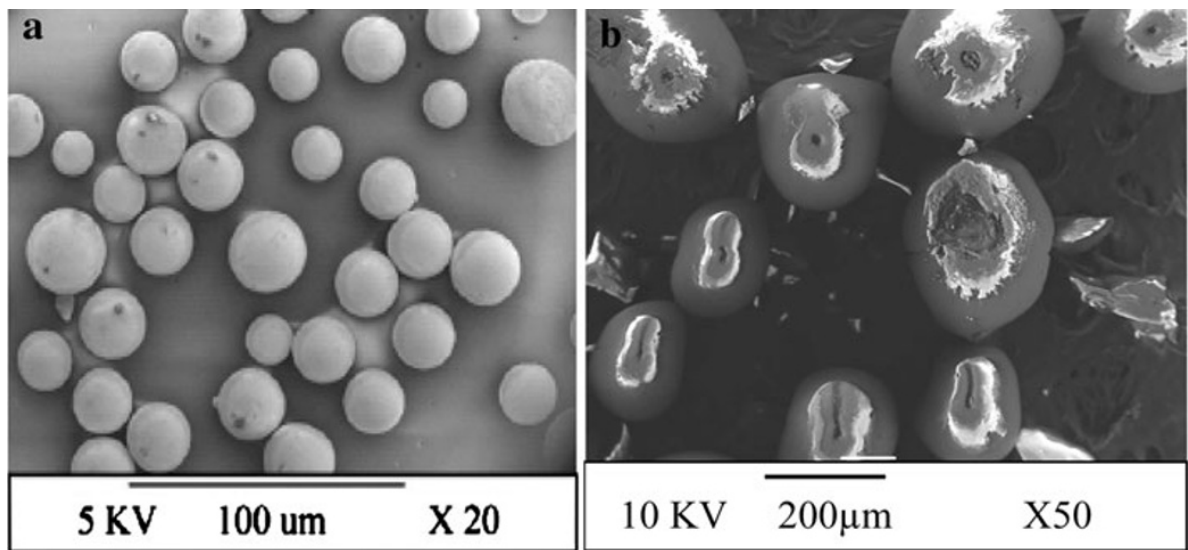

aqueous mixture was added in proper order to the effluent samples of arsenic and the total volume was adjusted to $25 \mathrm{~mL}$. After that the mixture was stirred for $16 \mathrm{~min}$ and the absorbance was measured at $553 \mathrm{~nm}$ through UVvisible spectrophotometer.

\section{Result and discussions}

\section{Characterization of DE-4 resin}

\section{FT-IR study}

The FT-IR spectra of Amberlite XAD-4 are previously reported (Nezhati et al. 2010). In order to elucidate the nitration and amination of Amberlite XAD-4, FT-IR spectra of both resins were recorded using $\mathrm{KBr}$ pellets. The presence of characteristic transmittance frequencies at 1,528 and $1,350 \mathrm{~cm}^{-1}$ for $\mathrm{NO}_{2}$ and $-\mathrm{C}-\mathrm{N}$ in the nitrated resin confirm the nitration of Amberlite XAD-4. Consequently, the appearance of new bands after reduction at 3,441 and $3,380 \mathrm{~cm}^{-1}$ for $-\mathrm{NH}_{2}$ confirms the reduction. These results are in agreement with the frequencies, which were already reported (Solangi et al. 2009). While after diazotization and impendent of the calix[4]arene derivative 3 , it has been observed that many characteristic bands have been emerged at $1,452,1,086$, and $815 \mathrm{~cm}^{-1}$, which can be attributed to $\mathrm{N}=\mathrm{N},-\mathrm{C}-\mathrm{O}-\mathrm{C}$ and terminal $\mathrm{CH}_{3}$ corresponding to the calix-moiety. These bands confirm the attachment of $\mathbf{3}$ onto Amberlite XAD-4 resin.

\section{SEM analysis}

Physicochemical parameters like surface morphology play key role in the sorption process. Surface of the resin not only provide active sites for the sorption of target metal ions but several other parameters like kinetics and thermodynamics of the sorption process also depend upon the morphology of the surface. Scanning electron microscopy furnishes a clear picture about the surface fixtures of a resin. Fig. 2a represent the surface image of pure Amberlite XAD-4, all the beads are clear with no foreign surface coverage material. After attachment of the calixarene derivative 3, the surface of the DE-4 resin undergoes prominent changes e.g., white layers in semicircular form, which increases the effective sorption area and provides active sites for sorption process (Fig. 2b).

\section{Effect of $p H$}

The most effective parameter, which affects the sorption capacity and reflects the sorption mechanism as well as the physicochemical nature of the sorption, is the $\mathrm{pH}$ of sorption medium. In this study, the sorption of A(III) onto DE-4 resin was examined through static method at different $\mathrm{pH}$ ranging from 2 to 14 with an initial As(III) concentration of $30 \mu \mathrm{g} \mathrm{L}^{-1}$ and a contact time of $1 \mathrm{~h}$. Slow dissociation of arsenic $\left(\mathrm{H}_{3} \mathrm{AsO}_{3}\right)$ occur at near neutral $\mathrm{pH}$ values (7-9) which results the formation of arsenite ion. This partially neutral and partially negatively charged arsenite ion is attracted to the positively charged (below 8.2) surface of

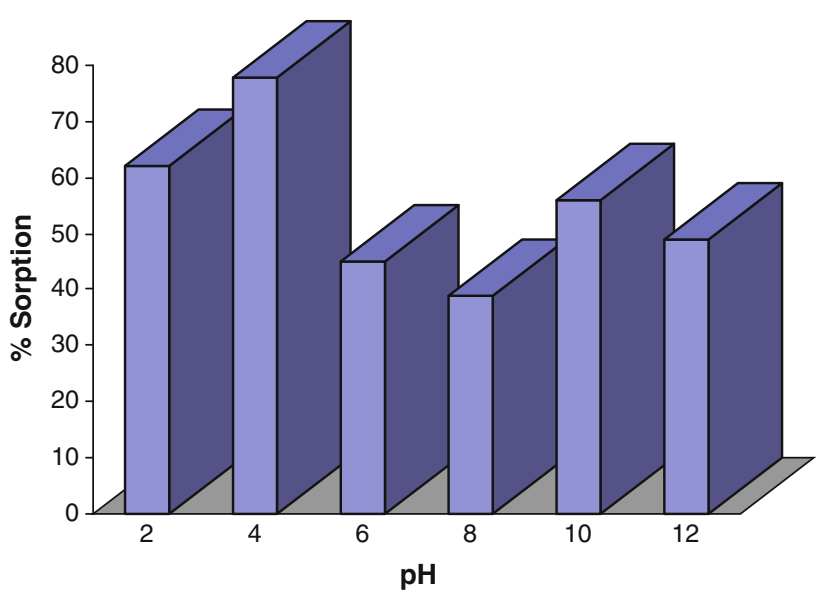

Fig. 3 Effect of $\mathrm{pH}$ on the sorption of As(III) onto DE-4 resin 
the resin (Budinova et al. 2006). Maximum sorption occurs at pH 4 (Fig. 3), may be due to stronger hydrogen bonding of As(III) at this $\mathrm{pH}$. All the sorption studies were carried out at this optimum $\mathrm{pH}$.

\section{Sorption modeling}

Several parameters like service time, sorption capacity, rate constant, etc. and their inter relation could be evaluated using column sorption models. The bed depth service time (BDST) model provides solution to calculate and optimize all these parameters (Lehmann et al. 2001). The BDST model can be expressed by Eq. (2)

$t_{\mathrm{b}}=\frac{q_{0}}{C_{0} V} M-\frac{1}{K C_{0}} \ln \left(\frac{C_{0}}{C_{\mathrm{t}}}-1\right)=a M+b$

where $t_{\mathrm{b}}$ is the bed service time, $q_{0}$ the sorption capacity, $C_{0}$ the initial concentration, $M$ is the amount of resin, $C_{\mathrm{t}}$ is the effluent concentration, $K$ is the sorption rate constant and $V$ is the flow rate. The value of sorption capacity $q_{0}$ and $K$ can be calculated from intercept and slope of the plot of $t_{\mathrm{b}}$ versus $M$, respectively. All the BDST model parameters and the column exhaustion time $t_{\mathrm{e}}$ are expressed in Table 1.

\section{Effect of bed height}

Bed height is an important parameter, which describes the number of active sites. The shape, i.e., steepness of the breakthrough curve and indirectly the rate of sorption both depend upon the height of the column bed. Sorption rate becomes slower by increasing bed height; however, sorption efficiency increases. Larger bed heights give rise to greater contact time between the solute, i.e., sorbate and sorbent in the sorption process (Wood 2002; Ranjan et al. 2009). Three bed heights of 4,6 and $10 \mathrm{~cm}$ were tested and the experiments were carried out at optimum $\mathrm{pH}$ (i.e., $\mathrm{pH}$ 4); the concentration of $\mathrm{As}(\mathrm{III})$ was $30 \mu \mathrm{g} \mathrm{L}^{-1}$ and flow rate was $2 \mathrm{~mL} \mathrm{~min}^{-1}$.

Figure 4 represents the graphical representation of the effect of bed height; it is a plot between $C_{t} / C_{0}$ (the ratio of effluent concentration and initial concentration) versus time using different bed heights. It is evident from Fig. 4 that increase in bed height results an increase in throughput volume because of higher contact time. The shapes of the breakthrough curve become steeper at low contact time, which is due to rapid exhaustion of the bed. Metal sorption capacity as well as breakthrough time increases with the increase of bed height increases because of increase in effective sites of the resin (Maiti et al. 2008). From the breakthrough curve the bed capacity at breakthrough point can be determined using Eq. (3)

$q_{\mathrm{b}}=\frac{C_{0}}{m} \int_{0}^{V b}\left(1-\frac{C_{\mathrm{t}}}{C_{0}}\right) \mathrm{d} v$

where $q_{\mathrm{b}}\left(\mathrm{mg} \mathrm{g}^{-1}\right)$ and $m(\mathrm{~g})$ are bed capacity at breakthrough point and the bed mass while $C_{0}$ and $C_{\mathrm{t}}$ are the initial and effluent concentration $\left(\mathrm{mg} \mathrm{L}^{-1}\right) V_{\mathrm{b}}$ is the processed volume at breakthrough point.

\section{Effect of flow rate}

Effect of flow rate on sorption of As(III) was studied at different flow rates the i.e., $2-6 \mathrm{~mL} \min ^{-1}$ while keeping the $\mathrm{As}(\mathrm{III})$ concentration $\left(30 \mu \mathrm{g} \mathrm{L}^{-1}\right)$ bed height $(10 \mathrm{~cm})$ and $\mathrm{pH} 4$ constant. From Fig. 5 it is clear that as the flow rate increases the breakthrough time, sorption capacity, exhaustion time, and column efficiency decreases. It may be due less contact time and slower diffusion of solute particles and rapid saturation of resin bed (Onyango et al. 2009).
Table 1 Parameters of BDST model

\begin{tabular}{lccclll}
\hline Process parameters & $V_{\text {effe }}(\mathrm{mL})$ & $t_{\mathrm{b}}(\mathrm{min})$ & $\mathrm{pH}$ & $t_{\mathrm{e}}(\mathrm{min})$ & $K_{\mathrm{b}}\left(\mathrm{L} \mathrm{\mu g}^{-1} \mathrm{~min}^{-1}\right)$ & $q_{\mathrm{b}}\left(\mu \mathrm{g} \mathrm{g}^{-1}\right)$ \\
\hline Bed height $(\mathrm{cm})$ & & & & & & \\
4 & 60 & 3 & 4 & 15 & 0.035 & 234 \\
6 & 116 & 7 & 4 & 29 & 0.053 & 305 \\
10 & 206 & 11 & 4 & 34 & 0.062 & \\
Initial concentration $\left(\mu \mathrm{g} \mathrm{L}{ }^{-1}\right)$ & & & & & 170 \\
40 & 44 & 6 & 4 & 22 & 0.040 & 198 \\
60 & 52 & 8 & 4 & 26 & 0.046 & 245 \\
100 & 60 & 11 & 4 & 30 & 0.056 & 410 \\
Flow rate $\left(\mathrm{mL} \mathrm{min}^{-1}\right)$ & & & & & & 228 \\
2 & 74 & 15 & 4 & 37 & 0.765 & 312 \\
4 & 62 & 10 & 4 & 31 & 0.487 & 0.293 \\
6 & 48 & 6 & 4 & 24 &
\end{tabular}




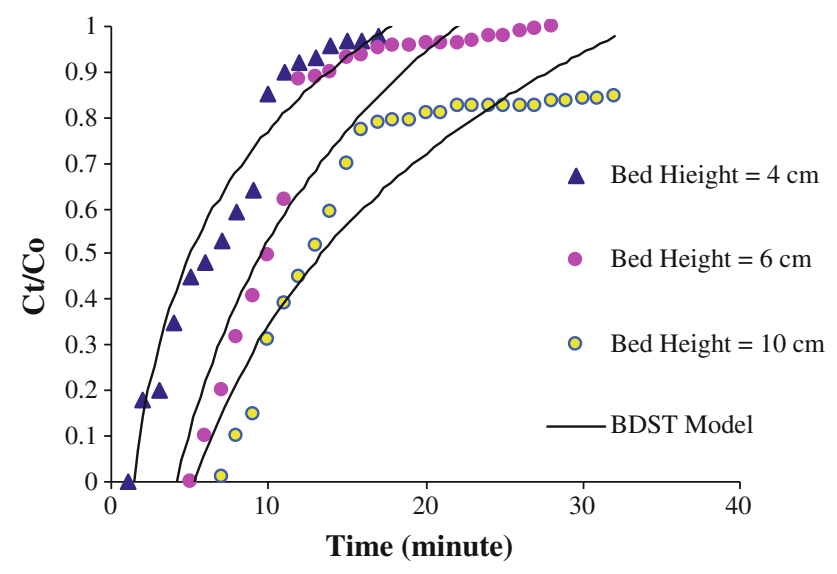

Fig. 4 Effect of bed height on the sorption of As(III) by DE-4 resin at flow rate of $2 \mathrm{~mL} \mathrm{~min}^{-1}, C_{0} 30 \mu \mathrm{g} \mathrm{L}^{-1}$ and $\mathrm{pH} 4$

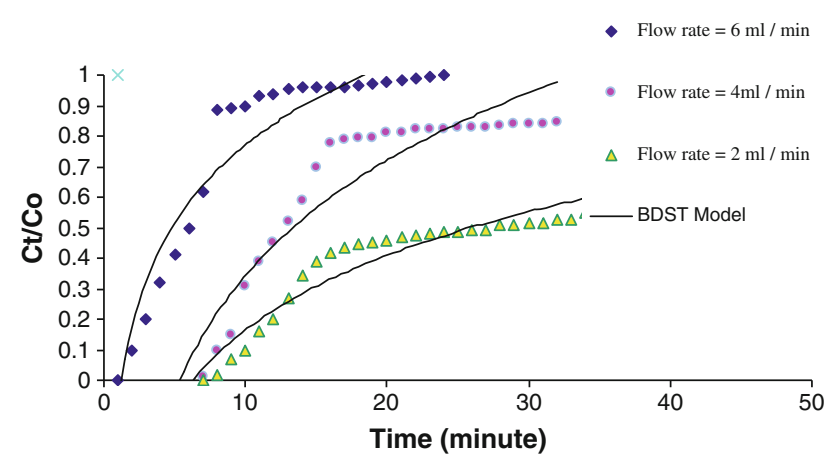

Fig. 5 Effect of flow rate on the sorption of As(III) by DE-4 at flow rate of $2 \mathrm{~mL} \mathrm{~min}^{-1}, C_{0} 30 \mu \mathrm{g} \mathrm{L}^{-1}$ and $\mathrm{pH} 4$

\section{Effect of concentration}

Effect of initial concentration on sorption of As(III) onto DE-4 was tested using three different concentrations of As(III), i.e., 40, 60, and $100 \mu \mathrm{g} \mathrm{L}^{-1}$ (Fig. 6). During the experiment the bed height and flow rate were kept constant. It has been observed that the value $K$ (the sorption rate constant) increases with the increase in initial concentration as calculated from Eq. 2. Meanwhile, the sorption capacity of the DE-4 resin increases because of the availability of unlimited active site at higher initial concentration as compare to low concentration. From the breakthrough curves at different flow rates it has been noticed that increasing the inlet concentration breakthrough point decreases. The volume of processed water at breakthrough point also increases by increasing concentration. At higher initial concentration of As(III) the rate of sorption become faster due to increase in driving force and faster coverage of the active sites (Islam et al. 2010).

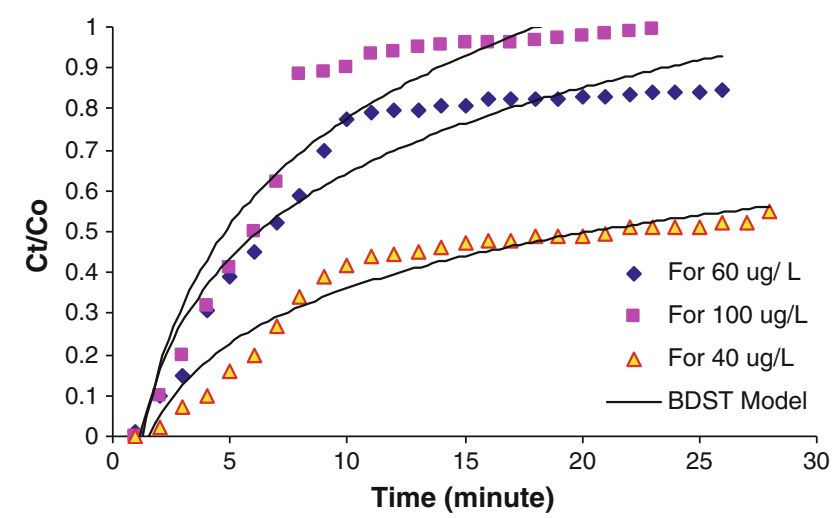

Fig. 6 Effect of initial concentration on the sorption of As(III) by DE-4 resin at flow rate of $2 \mathrm{~mL} \mathrm{~min}^{-1}, C_{0} 30 \mu \mathrm{g} \mathrm{L}^{-1}$ and $\mathrm{pH} 4$

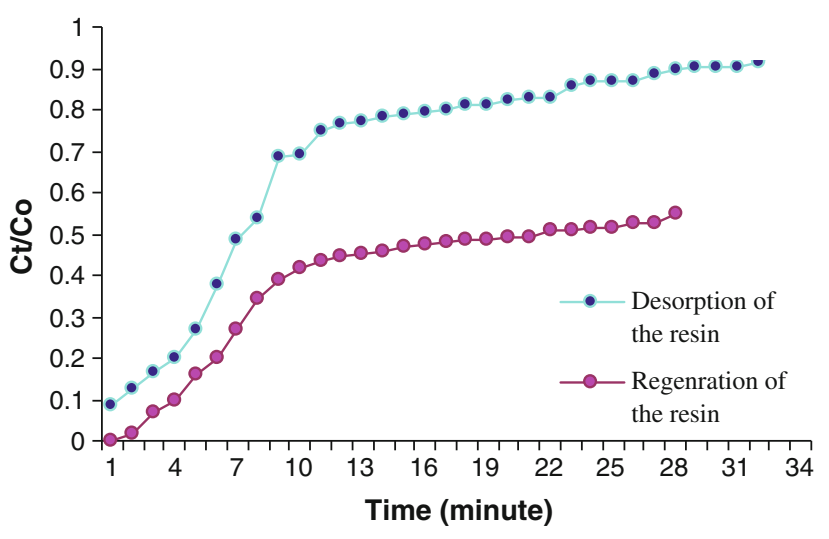

Fig. 7 Desorption/regeneration of the DE-4 resin at flow rate of $2 \mathrm{~mL} \mathrm{~min}{ }^{-1}, \mathrm{C}_{0} 30 \mu \mathrm{g} \mathrm{L}^{-1}$ and $\mathrm{pH} 4$

\section{Desorption/regeneration of the DE-4 resin}

Desorption is an indicator of the resin reusability and stability. In this study desorption was carried out using $5 \%$ $\mathrm{HNO}_{3} / \mathrm{NaOH}$ at the flow rate of $2 \mathrm{~mL} \mathrm{~min}{ }^{-1}$. The volume processed was $50 \mathrm{~mL}$ for the desorption process, which completed in $7 \mathrm{~min}$. In the first desorption cycle total of $\approx 1-2 \%$ loss was observed in sorption capacity and breakthrough occur after 3 min. After desorption the DE-4 resin column was washed with deionized water was ready again for reuse (Fig. 7).

\section{Thermodynamic study}

Temperature control in column sorption helps in evaluation of column performance in field under different environmental conditions. Moreover, it also facilitates industrial application of column at different temperatures. In this study effect of temperature on column sorption was studied from 298 to $338 \mathrm{~K}$ (Fig. 8). Sorption at different

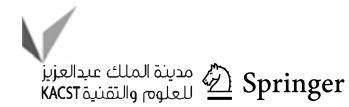




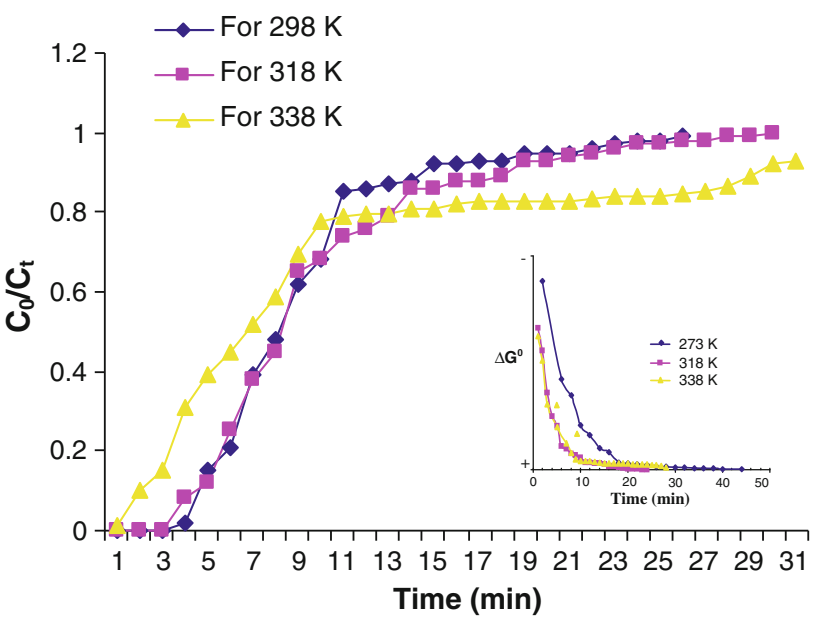

Fig. 8 Effect of temperature on sorption of As(III) onto the DE-4 resin at flow rate of $2 \mathrm{~mL} \mathrm{~min}^{-1}, C_{0} 30 \mu \mathrm{g} \mathrm{L}^{-1}$ and $\mathrm{pH} 4$. Inset graph shows the free energy pattern with respect to time at different temperatures

temperatures helps in determining different thermodynamics parameters, such as change in Gibb's free energy, enthalpy, entropy, etc. These parameters provide information about the nature and feasibility of the column sorption process (Sarin et al. 2006). The relation between Gibb's free energy and equilibrium constant can be expressed by Eq. (4)

$\Delta G^{0}=-R T \ln K_{\mathrm{c}}$

where $T$ is the temperature in Kelvin, $R$ is the ideal gas constant $\left(8.314 \mathrm{~J} \mathrm{~mol}^{-1} \mathrm{~K}\right)$ and $K_{\mathrm{c}}$ is the equilibrium constant, which can be determined by applying Eq. (5)

$K_{\mathrm{c}}=C_{\mathrm{a}} / C_{\mathrm{e}}$

where $C_{\mathrm{a}}$ is the sorbed concentration and $C_{\mathrm{e}}$ is the equilibrium concentration. The relation between equilibrium constant and enthalpy $\left(\Delta H^{0}\right.$, entropy $\left(\Delta S^{0}\right)$ can be expressed by Eq. (6)

$\ln K_{c}=\frac{\Delta S^{0}}{R}-\frac{\Delta H^{0}}{R T}$.

By plotting $\ln K_{\mathrm{c}}$ versus $1 / T$, the values of $\left(\Delta H^{0}\right)$ and $\left(\Delta S^{0}\right)$ can be calculated from the slope and intercept, respectively. From the experimental results it has been observed that the sorption of arsenite onto DE-4 resin is exothermic in nature, which confirms that sorption of As(III) onto DE-4 resin is favorable and effectively sorbs As(III) up to $66{ }^{\circ} \mathrm{C}$ from aqueous media.

In order to get the inside picture of Gibb's free energy profile in column sorption, change in Gibb's free energy with respect to time are plotted as shown in Fig. 8 (subgraph). It has been observed that with the passage of time at constant temperature the Gibb's free energy changes from negative to positive, i.e., from spontaneous to nonspontaneous process. The non-spontaneous tendency of the system indicates the effectiveness of the sorption process (Maiti et al. 2008). Similar behavior was observed for entropy and enthalpy also. The scale is kept limited between negative and positive signs for simplicity. Negative (spontaneous changes) and positive (non-spontaneous changes) signs on $y$-axis show the negative and positive values of Gibbs free energies.

\section{Thermal study}

Thermo-analytical study of the resin provides the thermal profile of resin and hence the temperature stability of the modified resin. From the DSC curve heat content of the resin, i.e., enthalpy of the resin can be calculated. Thermal behavior of DE-4 resin before and after sorption
Fig. 9 Differential scanning calorimetric (DSC) study of DE-4 resin

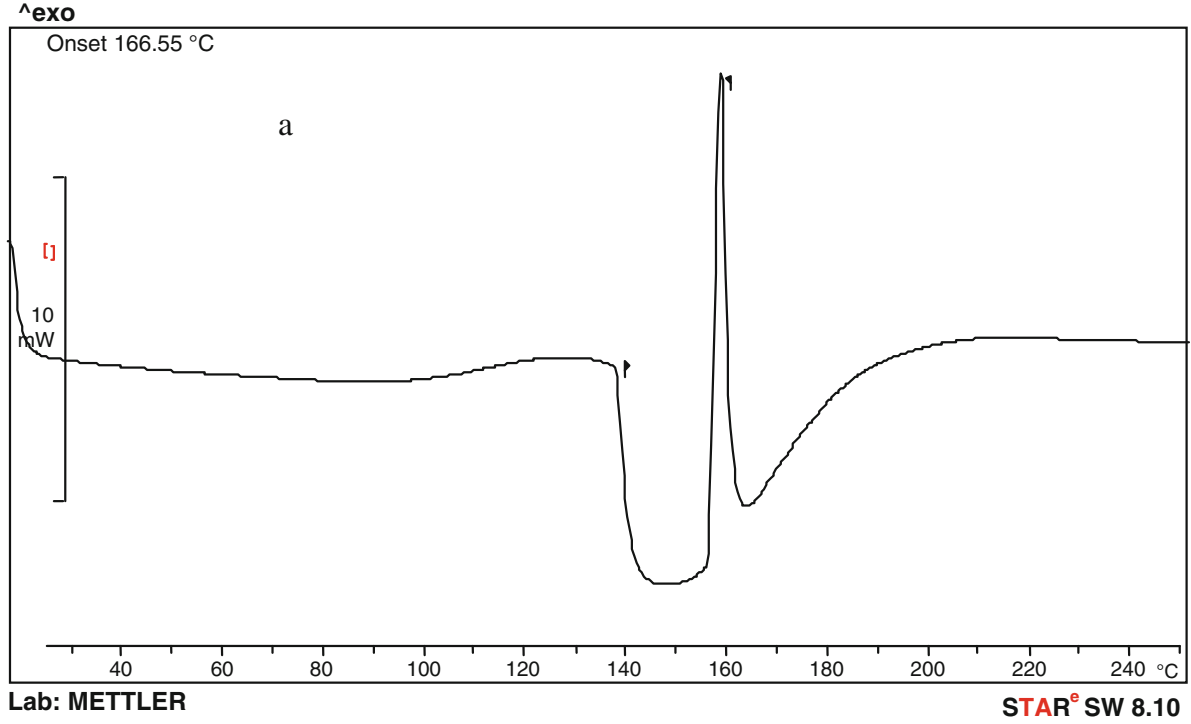




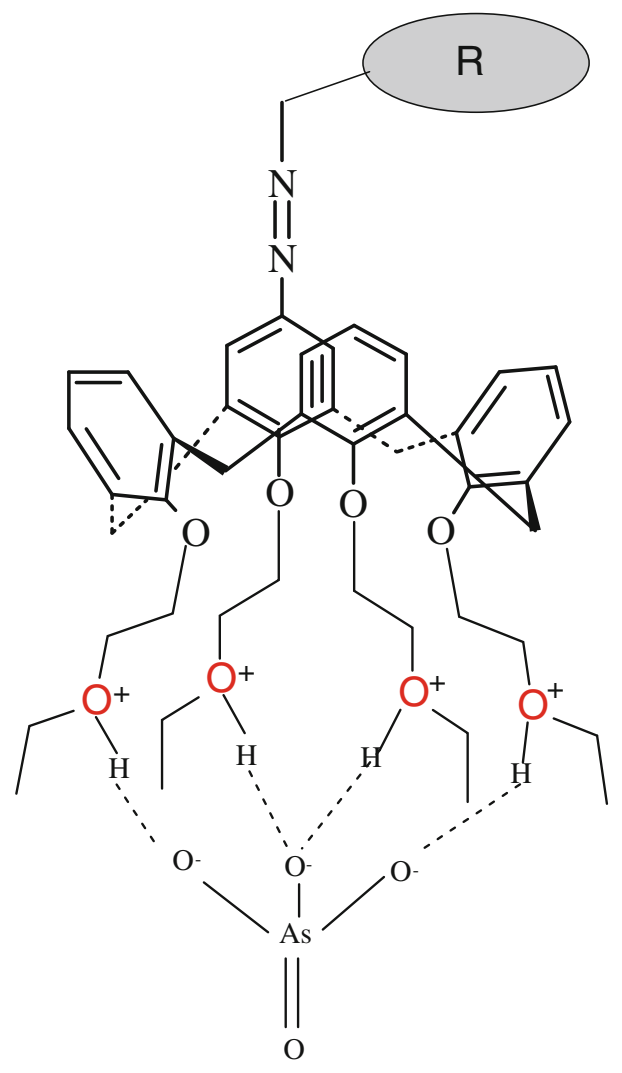

$\mathrm{R}=$ Amberlite $\mathrm{XAD}-4$

Fig. 10 Proposed As(III) sorption mechanism

process has been evaluated by DSC. The information obtained from both the curves indicates two types of changes with same pattern (Fig. 9). Both curves show one exothermic and one endothermic peak, and no change in behavior before and after sorption. The endothermic peak, which starts at $130{ }^{\circ} \mathrm{C}$ may be assigned to water loss (Bhaskar et al. 2004), while the exothermic peak at $166{ }^{\circ} \mathrm{C}$ show the decomposition of the attached calixarene derivative 3. Similar pattern was also observed in Fig. 9. The enthalpy values calculated from both the curves are in close agreement with those obtained from thermodynamic study.

\section{Proposed sorption mechanism}

From the experimental observations, it can be concluded that the sorbent interact strongly with the target ions. These interactions may be through hydrogen bonding between the arsenic ions and protonated oxygens present in etheric binding sites of calix-moieties appended onto DE-4 resin. Based on these observations following sorption mechanism could be proposed (Fig. 10).

\section{Conclusion}

The study elaborates extensive study on column sorption of As(III) onto polymeric resin DE-4. The whole sorption process may be controlled by optimized parameters. The resin DE-4 has been found to sorb As(III) effectively up to $88 \%$ at optimum $\mathrm{pH} 4$. Column sorption was tested at different bed heights, flow rates, and initial concentration. The maximum sorption efficiency obtained through column sorption is $412 \mu \mathrm{g} \mathrm{g}^{-1}$ of resin under optimum conditions. The resin ability toward regeneration was also tested and has been found regenerable using $5 \%$ solution of $\mathrm{NaOH} /$ $\mathrm{HNO}_{3}$. Thermal behavior at various temperatures by DSC was also investigated and it has been found that the DE-4 resin is stable up to $166^{\circ} \mathrm{C}$. High temperature stability shows that the DE-4 resin may find its applicability in various industrial processes where high-temperature water purification is required.

Acknowledgments The authors are highly thankful to the Higher Education Commission (PIN No. 063-142830-Ps3-234/HEC/Sch/ 2006) Islamabad and the National Center of Excellence in Analytical Chemistry, University of Sindh, Jamshoro-Pakistan, for the financial support of this work.

Open Access This article is distributed under the terms of the Creative Commons Attribution License which permits any use, distribution, and reproduction in any medium, provided the original author(s) and the source are credited.

\section{References}

Akceylan E, Yilmaz M, Bartsch RA (2006) Immobilization of cyclic alkylamine calix[4]arene derivatives on Merrifield resin: evaluation of extraction ability toward dichromate. J Macromol Sci Pure Appl Chem 43:477-486

Bhaskar M, Aruna P, Jeevan RJG, Radhakrishnan G (2004) [ $\beta]$ Cyclodextrin-polyurethane polymer as solid phase extraction material for the analysis of carcinogenic aromatic amines. Anal Chim Acta 509:39-45

Budinova T, Petrov N, Razvigorova M, Parra J, Galiatsatou P (2006) Removal of arsenic(III) from aqueous solution by activated carbons prepared from solvent extracted olive pulp and olive stones. Ind Eng Chem Res 45:1896-1901

Chen R, Zhang Z, Feng C, Huc K, Li M, Li Y, Shimizu K, Chen N, Sugiura N (2010) Application of simplex-centroid mixture design in developing and optimizing ceramic adsorbent for $\mathrm{As}(\mathrm{V})$ removal from water solution. Microporous Mesoporous Mater 131:115-121

Durmaz M, Zor E, Kocabas E, Bingol H, Akgemci EG (2011) Voltametric characterization of selective potassium ion transfer across micro-water/1,2-dichloroethane interface facilitated by a novel calix[4]arene derivative. Electrochim Acta. doi: 10.1016/ j.electacta.2011.04.003

EPA (2002) Office of ground water and drinking water implementation guidance for the arsenic rule, EPA Report-816-D-02-005 (I3-I4). USEPA, Cincinnati 
Genorio B, He T, Meden A, Polanc S, Jamnik J, Tour JM (2008) Synthesis of self-assembly of thio derivatives of calix[4]arene on Noble metal surfaces. Langmuir 24:11523-11532

Gutsche CD, Lin LG (1986) Calixarenes 12. Synthesis of functionalized calixarenes. Tetrahedron 42:1633-1640

Islam A, Laskar MA, Ahmad A (2010) Characterization and application of 1-(2-Pyridylazo)-2-naphthol functionalized Amberlite XAD-4 for preconcentration of trace metal ions in real matrices. J Chem Eng Data 55:5553-5561

Kamboh MA, Solangi IB, Sherazi STH, Memon S (2009) Synthesis and application of calix[4]arene based resin for the removal of azo dyes. J Hazard Mater 172:234-239

Kartinen E, Christopher M (1995) An overview of arsenic removal processes. Desalination 103:79-88

Kopanica M, Novotny L (1998) Determination of traces of arsenic(III) by anodic stripping voltammetry in solutions, natural waters and biological material. Anal Chim Acta 368:211-218

Lehmann M, Zouboulis AI, Matis KA (2001) Modeling the sorption of metals from aqueous solutions on goethite fixed beds. Environ Pollut 113:121-128

Maiti A, DasGupta S, Basu JK, De S (2008) Batch and column study: adsorption of arsenate using untreated Laterite as adsorbent. Ind Eng Chem Res 47:1620-1629

Maji SK, Pal A, Pal T, Adak A (2007) Modeling and fixed bed column adsorption of As(III) on laterite soil. Sep Sci Technol 56:284-290

Memon S, Yilmaz A, Roundhill DM, Yilmaz M (2004a) Synthesis of polymeric calix[4]arene dinitrile and diamino-derivatives: exploration of their extraction properties towards dichromate anion. J Macromol Sci Pure Appl Chem 4:433-447

Memon S, Yilmaz M, Roundhill DM (2004b) Remediation and liquid-liquid phase transfer extraction of chromium (VI). Collect Czech Chem Commun 69:1231-1250

Minhas FT, Solangi IB, Memon S, Bhanger MI (2010a) Kinetic study of $\mathrm{Pb}(\mathrm{II})$ transport through a bulk liquid membrane containing calix[6]arene hexaester derivative as carrier. Sep Sci Tech 45:1448-1455

Minhas FT, Memon S, Bhanger MI (2010b) Synthesis and characterization of novel calix[4]arene piperazine derivative for the extraction of transition metals and dichromate ions. J Incl Phenom Macrocycl Chem 67:295-302

Nezhati MN, Panahi HA, Moniri E, Kelahrodi SR, Assadian F, Karimi M (2010) Synthesis, characterization and application of allyl phenol modified amberlite XAD-4 resin for preconcentration and determination of copper in water samples. Korean $\mathbf{J}$ Chem Eng 27:1269-1274

Onyango MS, Leswifi TY, Ochieng A, Kuchar D, Otieno FO, Matsuda H (2009) Breakthrough analysis for water de-fluoridation using surface-tailored Zeolite in a fixed bed column. Ind Eng Chem Res 48:931-937

Pillai A, Sunita G, Gupta VK (2000) A new system for the spectrophotometric determination of arsenic in environmental and biological systems. Anal Chim Acta 408:111-115
Qazi MA, Qazi MA, Qureshi I, Memon S (2010a) A highly copper selective chromogenic calix[4]arene derivative. New J Chem 34:2579-2586

Qazi MA, Qureshi I, Memon S (2010b) Calix[4]arene based chemosensor for selective complexation of $\mathrm{Cd}(\mathrm{II})$ and $\mathrm{Cu}(\mathrm{II})$. J Molecul Struct 975:69-77

Qazi MA, Qureshi I, Memon S (2010c) Evaluation of complexation behavior of Calix[4]arene derivative. Pak J Anal Environ Chem 11:53-58

Qureshi I, Memon S, Yilmaz M (2008) Extraction and binding efficiency of Calix[8]arene derivative toward selected transition metals. Pak J Anal Environ Chem 9:96-100

Qureshi I, Qazi MA, Memon S (2009) A versatile calixarene derivative for transportation systems and sensor technology. Sens Actuat B Chem 141:45-49

Qureshi I, Memon S, Yilmaz M (2010) An excellent arsenic(V) sorption behavior of p-tertbutylcalix[8]areneoctamide impregnated resin. C R Chimie 13:1416-1423

Ranjan D, Talat M, Hassan SH (2009) Rice polish: an alternative to conventional adsorbents for treating arsenic bearing water by upflow column method. Ind Eng Chem Res 48:10180-10185

Sadana RS (1983) Determination of arsenic, in the presence of copper by differential pulse cathodic stripping voltammetry at a hanging mercury drop electrode. Anal Chem 55:304-307

Sarin V, Singh TS, Pant KK (2006) Thermodynamic and breakthrough column studies for the selective sorption of chromium from industrial effluents on activated eucalyptus bark. Biores Technol 97:1986-1993

Shih MC (2005) An overview of arsenic removal by pressure-driven membrane processes. Desalination 172:85-97

Solangi IB, Memon S, Bhanger MI (2009) Synthesis and application of a highly efficient tetraester calix[4]arene based resin for the removal of $\mathrm{Pb}^{2+}$ from aqueous environment. Anal Chim Acta 638:146-153

Waypa J, Elimelech M, Hering J (1997) Arsenic removal by RO and NF membranes. J Am Water Works Assoc 89:102

WHO (1996) Guidelines for drinking-water quality, health criteria and other supporting information, 2nd edn, World Health Organization, vol 2, pp 940-949

Wolthers M, Charlet L, Weijden CV, Peter R, Linde V, Rickard D (2005) Arsenic mobility in the ambient sulfidic environment: Sorption of $\operatorname{arsenic}(\mathrm{V})$ and arsenic(III) onto disordered mackinawite. Geochim Cosmochim Acta 69:3483-3492

Wood GO (2002) Quantification and application of skew of breakthrough curves for gases and vapors eluting from activated carbon beds. Carbon 40:1883-1890

Wu K, Wang H, Liu R, Zhao X, Liu H, Qu J (2011) Arsenic removal from a high-arsenic wastewater using in situ formed $\mathrm{Fe}-\mathrm{Mn}$ binary oxide combined with coagulation by poly-aluminum chloride. J Hazard Mater 185:990-995

Zouboulis AI, Katsoyiannis IA (2002) Arsenic removal using iron oxide-loaded alginate beads. Ind Eng Chem Res 41:6149-6155 